\title{
An Empirical Investigation of Nutrition and Health Claims in Shaping Consumer Pre-Purchase Intentions
}

\author{
Shumaila Kashif 1 \\ Muhammad Zaki Rashidi ${ }^{2}$
}

\begin{abstract}
Due to increase in adverse effects of changing lifestyle all around the globe, health consciousness is increasing among people resultantly the belief that healthy food intake is better than using medicine has given rise to the development and marketing of healthy packaged food products commonly known as functional food. The purpose of this research is to investigate consumer's attitude towards nutrition and health claims products and their pre-purchase intentions. The aim is to analyze underlying motivations which form the basis of attitudes viz. health consciousness, health benefits and health beliefs. This research is an empirical investigation, conducted through a quantitative survey by selecting 500 respondents from three different supermarkets in Karachi. Correlation and regression analyses are used to find out the relationship among the variable and ANOVA is employed to evaluate the moderating effect of socio-demographic variables on pre-purchase intentions. Five in-depth interviews and two focus groups are also conducted to develop an understanding on consumers' beliefs towards these claims. The results reveal that health consciousness, health benefits and health beliefs explain variation in attitude towards nutrition and health claim products and prepurchase intentions. Also, they are significantly correlated with each other except health belief. Significant effect of various socio-demographic variables are found such as married, young and educated females are more concerned about health and have high pre-purchase intentions as compared to the other groups. However, income does not affect other variables but influences purchase intentions among all age groups. The results provide insight to local healthy food products market, and food marketers may take expert opinion of nutritionists to endorse their products as, generally, respondents are skeptical about the claims. Also, claims should be communicated in a clear, comprehensible and less scientific way to increase consumer response to these products.
\end{abstract}

Keywords: Health beliefs and benefit, health consciousness, nutrition/health claims, prepurchase intention

\section{Introduction}

Healthy food intake is necessary to keep a healthy life style as it reduces the risk of various diseases, helps in leading a fulfilling life and aging gracefully. Malnutrition direly impacts upon natural immunity and human body becomes vulnerable to health complications. On the other hand, healthy diet may have a positive impact on human immune system. For example various studies have found out that high dietary fiber intake lowers coronary heart disease risk, control obesity and high blood pressure as well as cancers such as colon (Andersen et al., 1994). These diseases are simply a matter of making unhealthy choices about food which lacks proper nutrition.

${ }^{1}$ Shumaila Kashif is Lecturer at SMIU, Karachi, kashifshumaila@gmail.com ${ }^{2}$ Muhammad Zaki Rashidi is Assistant Professor, Management Sciences, SZABIST, Karachi, zaki@szabist.edu.pk \begin{tabular}{llll|l}
\hline JISR-MSSE & Volume 11 & Number 1 & Jaunary - June 2013 & 83
\end{tabular} 
In developed as well as in developing countries the life style of people is evolving and taking new forms. Increased urbanization, changing modes of transportation, and facilitation through electronic gadgets are reducing the physical activities (Koplan \& Dietz, 1999). Television and other print media are also promoting the consumption of high calorie food and drinks, while both young and adult are equally affected by the excessive use of fast food, and leading to increase the rate of obesity (Hernandez et al., 1999; Ruangdaraganon et al., 2002). Readyto-eat food is further altering the dietary patterns and choice of the urban consumers, and affecting the health negatively. One of the counter efforts to control the perilous life style and consumption of unhealthy food is the launch of nutritional and healthy food in the urban market.

Since the launch of nutrition and healthy food, a survey conducted by the Food Marketing Institute (FMI) and Prevention-Rodale annual study revealed that there is an increasing pattern in adopting healthy food among US consumers (FMI, 2004). In Pakistan this phenomenon is also observed and evident through the growing viewership of cooking programs where a substantial stress is laid upon on healthy food instead of using fast food.

As consumers grow health conscious, it provides opportunity to food manufacturing companies and brand owners to target this emerging market with new innovative products. Food manufacturers are feeding consumers' desire for more nutritious products by "reformulating" their products to create healthier versions (Dawson et al. 2008; Golan et al., 2009) as well as launching complete product line of healthier versions. During past few years, many companies have promoted their brands locally along with international markets. Brands need to take the drive for healthier products and increase consumers' commitment, loyalty and trust.

Marketing of nutritious/healthy food is done in two ways. First, providing information about nutritious value of a certain product; it also requires understanding and use of labeling as well promoting certain product categories as more healthy than the others. Secondly, it is done by improving nutrition/health value of existing products by reducing unhealthy contents and adding healthy nutrients. These products are advertised and sold on the basis of their health benefits and are experiencing high growth rates (Larson \& Grunert, 2003). Food market has experienced growth in each sector; however, healthy food sales exceeded over others (Mintel, 2006). Market of healthy products and functional food has been growing around the world and driven by economic, social and demographic trends. Also, culture, demographics and income affect the demand of healthy food in different parts of the world.

Information about the nutrient content of food is provided through nutrition labeling. Establishment of a clear regulatory system and its enforcement are very critical to build and gain consumers trust for making nutrition and health claims. It encourages healthy competition within the industry and foster innovation. The Nutrition Labeling and Education Act (NLEA) were first established in USA in 1990. It is comprehensive and its purpose is to increase awareness of general public about the health value of food they buy as well as to stress upon food product manufacturers to declare and improve the nutritional attributes of products. In UK and other European countries nutrition labeling regulation is controlled by Food Labeling Regulation 1996. Other countries have their respective food regulation laws (Moore, 2001). Pakistan has “The Pure Food Law 1960” which governs Food Labeling regulation. 
Increasing competition and plethora of products available in market have posed the question to what consumer rely on when making purchase decision. This process gets intricate when consumer is making conscious choice of buying healthy product which are shaped by their cultural and environmental background, religious/social beliefs towards different food and eating connection, education level, knowledge about food and nutrition they provide. These various factors are shaping consumers' attitude towards health/nutrition claims and they further differ from one region to other. Hence success of any product will rest on how well marketers understand the consumer behavior of each market and dynamics of socio/demographic factors influencing purchase intention.

This study aims to investigate the dynamics of consumer market for packaged healthy food products in Karachi to understand consumers' attitude towards nutrition and health claims of food products with regard to pre-purchase intentions on the basis of socioeconomic segmentations. The study is based on qualitative research conducted through in-depth interviews and focus group to explore consumer's level of understanding about nutrition/health claims and relating products they usually purchase. It then employs quantitative survey to test hypothesis formed on proposed conceptual framework and analyze the role of socio/demographic factors in explaining their pre-purchase intentions.

\subsection{Research Objectives}

- To evaluate the level of health consciousness of Pakistani consumers.

- To explore what health benefits are most important to drive customer purchase intentions.

- To investigate, if any positive or negative health beliefs exist in Pakistani society.

- To empirically find the relationship between health consciousness, health benefits and health beliefs in shaping attitudes towards nutrition value of food products.

- To explain and investigate the pre-purchase intentions on the basis of attitude towards nutrition/health claims.

- To identify the relationship between health consciousness, health benefits, health beliefs and pre-purchase intention.

- To segment the claims, pre-purchase intention and relationship on the basis of different socio-demographic groups.

\section{Literature Review}

It has been argued that customers are being enticed to see food items in different dimensions, meaning, as they believe judicious food choice can prevent them from diseases (Heasman \& Mellentin, 2001) because food items having greater nutritious content can cure or avert existing disease. Earlier, the focus was on reducing harmful ingredients (fats, sodium etc.), making food healthy. Currently, nutritious ingredients are added to conventional food to convert them into functional food. Functional Food is similar to conventional food, as consumed like standard diet on a regular basis, usual quantities and proven to reduce risk of specific disease apart from its basic nutrition functions (Doyon \& Labrecque, 2005).

\begin{tabular}{llll|l}
\hline JISR-MSSE & Volume 11 & Number 1 & Jaunary - June 2013 & 85
\end{tabular}


However, functional food is not a complete replacement of conventional food, but it provides another choice to the consumers (Dixon et al, 2006).

Attitude towards nutrition/health claim or overall evaluation towards healthy products form the basis of purchase intentions and can transform the actual behavior (Ajzen \& Fishbein, 1980). Theory of reasoned action is considered imperative in the studies of consumer behavior. Hale et al. (2003) in their research pointed out that theory of reasoned action has been tested in various studies to predict human behavior such as dieting (Sajwacz, Ajzen \& Fishbein, 1980), attitude towards genetically modified organism related to food (Sparks, Shepherd \& Frewer, 1995).

There is a plethora of products available in supermarkets claiming different health benefits through their labels. Therefore, a label has become one of the criteria upon which consumer can rely to differentiate among products while making complex decision (Giraud, 2005). However, food marketers only emphasize on the elements which provide health benefits but do not provide any information about unhealthy content e.g. low fat is promoted but extra sugars is not known (Andrews et al., 1998; Golodner, 1993; Ippolito and Mathios, 1994). Due to these deceptive portrayals consumers often misled by the health benefits claims made by advertisement about their product (Balasubramaniam \& Cole, 2002; Mazis and Raymond, 1997; Mueller, 1991). An acute perusal of various research studies reveals that there is a contradiction among the claims made by several researchers regarding the nutrient and healthy food. The contrast is due to the context in which these studies are conducted and time periods these claims are made.

It is indicated by various researches that consumers would like to read the nutrition information mentioned on the product but they have no idea of how to use it successfully (Drichoutis et al., 2006; Moorman, 1990) as well as many consumers do not have any knowledge in general (Chase, 1995). Some other researchers have found out that variation in consumer behavior exists on the basis of gender, education, age and income about use of labels and nutritional knowledge and belief about health claims (Burton and Andrews, 1996; Mueller, 1991; Nayga et al., 1998; Teisi et al., 1999)

In the US, about half of the consumers who think they are consuming healthy food, nutritional label is viewed as top three sources of information (IFICF, 2006). About 58\% use this nutrition facts panel (NFP) when deciding about buying a food or beverage, specifically if it is the first time purchase or choosing between two products with similar price (IFICF, 2004, 2005, 2006).

Growing health concerns, nutrition knowledge, attitude towards dietary recommendations and perceived influence of diet on health are considered to be important factors in determining consumers' dietary behavior. Bogue, Coleman and Sorenson (2005) in their research selected 340 Irish consumers from low-income and high-income groups through multistage cluster sampling to measure these determinants. About $47 \%$ of respondents agreed that type of food consumed can determine the health and the most commonly found conditions influenced by diet are obesity, heart diseases, high cholesterol and hypertension.

Gender is an important determinant in consumer dietary behavior. Women as compared to men are likely to conform to dietary guidelines and recommendations (Monneuse et al., 1997; 
Turrell, 1997). Attitude towards healthy food is significant predictor of consumers' food choice behaviour (De Graaf et al., 1997; Dennison and Shepherd, 1995), attitude of women towards healthy food is positive and they are more involved in the matter of health and diet than men (Monneuse et al., 1997) and this is even stronger if their age is 35 and above (Bogue, Coleman and Sorenson, 2005). Awareness about relationship of diet and health motivates a person to acquire further details enabling to make healthy eating choices (Blaylock et al., 1999). Women are significantly better on knowledge about nutrient, diet and health when compared with men (Buttriss, 1997; Turrell, 1997, Bogue, Coleman and Sorenson, 2005). Consumers from 35 to 54 age group have more knowledge of nutritients (Bogue, Coleman \& Sorenson, 2005). Harnack et al. (1997) also found that differences in choice of healthy food exist among different socio-economic strata.

In Europe, consumers are increasingly realizing the impact of food choice on health (Biacs, 2007). However, they tend to make use of technology in processing and adding functional ingredients in natural food more (e.g. genetically modified food, radiation effected food) contrary to US consumers (Bech-Larsen \& Grunert, 2003; Lusk et al., 2004; Lusk \& Rozan, 2005). Nevertheless, according to IFIC annual research $(2002 ; 2005)$ demand and awareness for functional foods is rising due to concerns of unhealthy lifestyles and prevention is better than Rx way. During 1990s, many researchers worked on reactions of consumers towards rapidly growing functional foods market in the US (Childs, 1997; Childs \& Poryzees, 1997; Gilbert, 2000; IFIC, 2000; Wrick, 1995). Generally, consumers in the US are very well aware of the concept of functional foods and make them a part of their diet (IFIC, 2000).

Asian consumer have a short term perspective on dietary choice of healthy food due to their mindsets and their knowledge about long term benefits of healthy diet intake is poor. This could be attributed to the fact that Asian consumers have old traditions on consumption patterns which influence their food choices. A qualitative study by AC Nielsen in 12 Asian countries suggested that eating choices are driven heuristically by familiarity of food, taste, etc and nutrition and health are secondary concerns. Also, their perception of nutritious/healthy food is defined socially rather than scientifically e.g. fatty food calories can be offset if combined with sour element. Implementation of nutrition/health labels is in early stages and not properly implemented. Moreover, culinary tastes, food beliefs, knowledge level and values are different with regard to food health. These contextual and regional drivers shape their attitude towards nutrition/health claims.

Many authors suggested that characteristics such as gender, socio-economic status, and level of education of consumers are more important while making a choice for any food related product (Verbeke, 2005, 2006; Urala \& Lahteenmaki, 2007). Several studies claimed that women are often found to be more familiar and frequent user of health or nutritious claimed products as compared to male (Childs and Proyzees, 1997; Verbeke, 2005, 2006). One of reason suggested is the role played by female in food choice particularly. While considering the age instead of gender, it is found that young people are less careful in making healthy food choice than middle-age or older people who are conscious about health matters and the consequences of the choice (Verbeke, 2006). Level of educated, socio-economic class and affordability are other factors which may affect the awareness and choice of nutrient food (Anttolainen et. al., 2001, Childs, 1997, deJong et. al., 2003, 2008, Hilliam, 1996, Poulsen, 1999). Although some researchers have presented contradictory findings as discussed above but the importance of above characteristics of in predicting food behavior cannot be denied (Dagevos, 2005).

\begin{tabular}{llll|l}
\hline JISR-MSSE & Volume 11 & Number 1 & Jaunary - June 2013 & 87
\end{tabular}




\section{Conceptual Framework}

The consumers' attitude forms the basis to predict pre-purchase intentions which are modrated by socio-demographic factors.

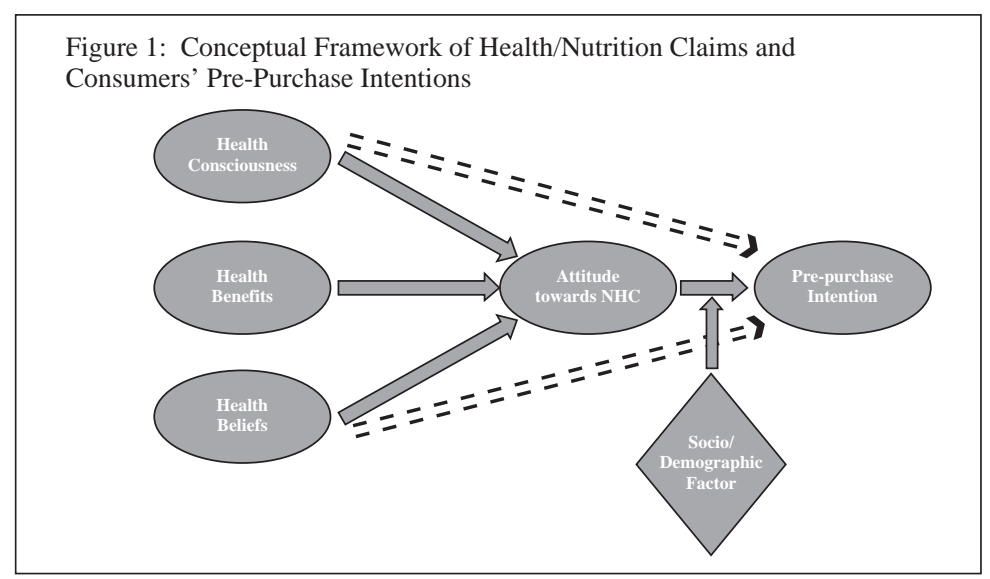

\section{Research Methodology}

This research is an exploratory and empirical investigation. Five in-depth interviews and two focus groups were conducted. A survey was also conducted to collect data for empirical analysis. The estimated population of the areas of sampling range from 0.3 million to one million and 125 respondents each were selected from three different supermarkets having more than two branches in Karachi and educational institutes.

Sampling technique is based on convenient sampling. People visiting supermarkets were approached. Respondents were briefed about the purpose of research and their consent to fill the questionnaire was taken. Respondents mainly consisted of house wives and young men and women. The questionnaires were personally administered in most of the cases. The adequate size of 500 respondents with $95 \%$ confidence interval visiting supermarkets was chosen. Out of 500 questionnaires 399 were returned with $79 \%$ response rate. Out of 399, 19 were incomplete and hence were rejected. In total, 380 questionnaires were accepted and analyzed further.

The questionnaire was designed to measure seven important constructs which were derived through literature review: a) health consciousness; b) health beliefs; c) health benefits; d) customer perception; e) attitude towards nutrition/health claims; f) pre-purchase intention; g) socio/demographic profile. The questions about pre-purchase intentions were taken from measures build up by Ajzen (1991) while other questions were extracted from literature such as a study of Urala (2006) which is based on various studies of functional food in Finland. Once the questionnaire was formulated, first, it was validated by other researchers and nutrition experts, than it was pilot-tested to improve the understanding and quality of items constructed in the local setting. All responses were measured through five-point Likert scale with " 1 " as strongly agree and " 5 " strongly disagree. Socio-demographic profile includes data pertaining to their gender, marital status, age, education, income was also collected. 


\section{Data Analysis and Discussion}

\subsection{Qualitative Research Findings}

Almost all the respondents answer that they do shop for packaged healthy food products although some of them mentioned that they do not buy it on regular basis. On the opinion about claims, $90 \%$ of the respondents (housewives, health conscious people visiting gym) said they do not believe them i.e. "no" "they are all fake" "don't believe". On the contrary, focus group discussion with young university student suggests that they do believe the claims and it make it easier for them to choose the right product and it is desirable. Healthy products which almost all respondents mentioned they regularly purchase or are aware of during both sessions were "Nesvita, low-fat yoghurts, Margarine, Pediasure, Horlicks, Complan, Fruit juices" hence can be categorized into four main categories:

- Enriched UHT milk (whole, skimmed and semi-skimmed)

- Dairy products (Low-fat yogurts, Cheese)

- Spreads (Margarine and Butter)

- Drinks (fruit juices, powdered healthy drinks)

Some respondents considered fiber biscuits (wheat) as healthy snacks however when they were asked to explain some popular functional food concepts such as probiotec yoghurts or drink they could not explain it although most of them have heard about it. General well being is the only benefit all respondents agreed on while shopping for healthy packaged food products as if they need to prevent disease would prefer to use medication. All respondents did agree that consumption of healthy food is necessary but they confess that their actual diet/consumption pattern suggest otherwise.

\subsection{Quantitative Research Findings}

First of all, reliability of overall scale was determined and measures were found to have internal consistency of Cronbach's alpha 0.71 which is considered good scale reliability. All variables of study were based on likert 5 point scale with 1 being strongly agree and 5 strongly disagree (see Table 1) where mean value of all variables is between 2.14 to 3.06 meaning responses are centered on neutral response. Highest mean value of 2.89 and 3.06 towards purchase intention shows customer attitude is positive which translate into purchase intentions. Standard deviation of most of the constructs is close to 0.5 showing average deviation from mean value relatively high deviations are of health consciousness (0.7) and purchase intention meaning respondents have different opinion about them. Table 2 stipulates socio/demographic profile of respondents.

Analysis of correlation matrix (Table 3) indicates highest positive correlation found between health consciousness and attitude towards nutrition/health claims $(0.382)$ followed by health consciousness and health benefits $(\mathrm{p}=0.370)$ whereas, very low and negative correlation exists between health consciousness and health beliefs $(p=-0.020)$. One-way ANOVA (Table 4$)$ was performed for multiple group comparison and significant differences are found on the basis of gender (health benefits $\mathrm{p}=0.000$, health beliefs $\mathrm{p}=0.002$, marital status (health benefits

\begin{tabular}{llll|l}
\hline JISR-MSSE & Volume 11 & Number 1 & Jaunary - June 2013 & 89
\end{tabular}


$\mathrm{p}=0.004$, health beliefs $\mathrm{p}=0.001, \mathrm{p}=$ attitude NHC 0.000 , age (health benefits $\mathrm{p}=0.016$, health beliefs $\mathrm{p}=0.029$, attitude NHC $\mathrm{p}=0.004$ ), and education (health consciousness $\mathrm{p}=0.000$, health benefits $p=0.000$, pre-purchase intentions $p=0.002$ ). However, pre-purchase intentions are significant only on the basis of income (pre-purchase intentions $\mathrm{p}=0.033$ ). Other values are not significant hence there is no significant difference.

Results of regression analysis are presented in (see Table 5). For H1, adjusted R square value (0.20) shows that $20 \%$ variations in attitude towards nutrition/health claim are explained by health consciousness, benefits and beliefs. Also, as the ANOVA calculated sig. value is 0.000 , which is lower than the tabulated value of 0.05 , showing that the independent variables explain the variation in dependent variable, therefore, there is no evidence to accept the null hypothesis hence it is rejected at alpha 5\%. It is then concluded that health consciousness, benefits and beliefs do explain variation in pre-purchase intentions. Also, the t-test sig. values for health consciousness, benefits and beliefs are below 0.05 which is highly significant supporting the above-mentioned conclusion.

On the other hand, value of adjusted $\mathrm{R}$ square is very low (0.06) in $\mathrm{H} 2$, showing very little variation in pre-purchase intentions is explained by health consciousness, benefits and beliefs. ANOVA calculated value is $\mathrm{p}=0.000$, which is lower than tabulated value of $\mathrm{p}=0.05$, hence significant in explaining the variation in pre-purchase intentions. Therefore, the null hypothesis cannot be accepted and it is concluded that health consciousness, health benefits and beliefs explain variation in pre-purchase intentions. The t-test sig. value for health benefits is $p=<0.05$ hence not significant, whereas, for pre-purchase intentions, health consciousness and health beliefs is highly significant i.e., $\mathrm{p}=0.000$.

For H3, value of adjusted R square is very low 0.094 showing very little variation in prepurchase intention is explained by attitude towards nutrition/health claims. ANOVA calculated value is 0.000 , which is lower than tabulated value of 0.05 , hence significant in explaining the variation in pre-purchase intentions. Therefore, the null hypothesis is rejected and it is concluded that attitude towards nutrition/health claims explains variation in pre-purchase intentions. The t-test sig. value for pre-purchase intentions is above 0.05 hence not significant whereas for attitude towards nutrition/health claim is highly significant i.e. 0.000 strengthening the above-mentioned conclusion.

Analysis of main socio/demographic variables depicts that most of the respondents were male $(58 \%)$ as compare to female $(41 \%)$, almost equally distributed among single and married. The most prominent age group in respondents is $26-35(47 \%)$ with bachelor degree $(41 \%)$ followed by masters $(37 \%)$ hence educated. The respondents from each income group were part of the sample. Therefore, the sample can be considered as representative in terms of gender, income, and education.

Analysis of descriptive statistics shows that people are moderately health conscious, have somewhat negative health beliefs towards packaged nutritious/healthy food products and not interested in the health benefits offered by them. On the contrary, they do intend to purchase the products which seem to be influenced by other factors i.e., advertisement etc. At $1 \%$ significant level highest correlation is found out between health consciousness and attitude towards nutrition/health claims $(0.382)$ while insignificant negative correlation is found between health consciousness and health beliefs $(-0.020)$. 
Married women seem to be more health conscious compared to men; however, as the age increases health consciousness decreases. Education and income do influence the health consciousness, attitude towards nutrition/health claims and pre-purchase intentions.

ANOVA reveals significant differences between following socio-demographic factors:

- Male and female respondents on health beliefs and health benefits

- Marital status on health benefits, beliefs and attitude towards nutrition/health claims

- Age on health benefit and beliefs

- Education on health consciousness, benefits and pre-purchase intentions

- Income on purchase intentions only

- Family members on health consciousness, benefits, belief, attitude towards NHC and pre-purchase intonations.

Regression results suggest that independent variables explain variations in dependent variables as significant values are less than 0.05 ; however, low adjusted $\mathrm{R}$ value show very low variation explained which may be due to high colinearity in variables.

\section{Conclusion}

The study analyzed the local market health dynamics in shaping consumer attitude towards nutrition/health claims. Findings reveal that the market is in the early stage of evolution and there is a scant familiarity with the concepts of healthy food products. People do not have clear understanding of importance of consuming packaged healthy food products and their significance in preventing and curing diseases. Survey shows an average predisposition towards health consciousness and health is not given due consideration.

The health benefit which drives most consumers' pre-purchase intentions is general wellbeing. It was confirmed from both qualitative and quantitative analysis as more than $60 \%$ respondents believe that they can stay healthy by packaged healthy food intake and feel energetic after consuming these foods. In particular, married and educated women are more concerned about health benefits and have higher purchase intentions.Significant differences were found between various socio/demographic factors such as gender on health beliefs and benefits, single women have different attitude towards nutrition/health claims, more educated people with less family members and high income consumers are more likely to purchase packaged healthy products. Positive correlations were found between health consciousness, health benefits, attitude towards nutrition/health claims and they were significantly linked with pre-purchase intentions. Therefore, health consciousness, positive health beliefs, health benefits are important constituents in shaping positive attitude towards nutrition/health claims.

Consumers have somewhat positive attitude towards nutrition/health claims and favorable pre-purchase intentions but due to lack of knowledge, awareness and clear understanding of the benefits they are confused. It also seems that respondents have high purchase intentions but relatively low health consciousness, health benefits and belief which could be due to the influence of advertisement and trend following (in females) but absence of rational reasoning

\begin{tabular}{lll|l}
\hline JISR-MSSE & Volume 11 & Number 1 & Jaunary - June 2013
\end{tabular}


to consume. Another important conclusion drawn was related to consumer perception about nutrition/health claims. About $40 \%$ have neutral perception and $24 \%, 13 \%$ believed that claims are marketing gimmick. This fact was also second by interview and focus groups discussions.

There is relatively a few local manufacturing of packaged healthy food products and market is dominated by enriched UHT milk, fruit juices, margarine etc. Food manufacturing companies should introduce popular healthy food alternative such as probiotec yoghurt, soy drinks. Also, to form a positive health perception in consumer's mind, nutritionist/dieticians should be used to endorse nutrition/health claims to neutralize the effect of commercialized interest. Considering the fact that general wellbeing and improved physical performance are most desired benefits they can be used to in marketing of packaged healthy food products. Due to lack of awareness and knowledge about the function of healthy ingredients on health, it is necessary to communicate nutrition/health claim in more clear, understandable and less scientific way.

\section{References}

A C Nielsen (2005). Life Choices Survey.

Ajzen, I. \& Fishbein, M. (1980). Understanding attitudes and predicting social behavior. Englewood Cliffs, NJ: Prentice-Hall.

Ajzen, I. (1991). The theory of planned behavior. Organizational Behavior and Human Decision Processes, 50, 179-211.

Anderson, J.W., Smith, B.M. \& Gustafson, N. J. (1994). Health benefits and practical aspects of high-fiber diets. The American Journal of Clinical Nutrition, 59(5), 124 - 147.

Andrews, J.C., Netemeyer, R.G. \& Burton, S. (1998). Consumer generalizations of nutrient content claims in advertising. Journal of Marketing, 62(4), 62-75.

Balasubramanian, S. \& Cole, C. (2002). Consumers' search and use of nutrition information: the challenge and the promise of the Nutrition Labeling and Education Act. Journal of Marketing, 66 (3), 112-27.

Bech-Larsen, T.K. \& Grunert, G. (2003). The perceived healthiness of functional foods: a conjoint study of Danish, Finnish and American consumers' perception of functional foods. Appetite, 40, 9-14.

Biacs, P. A. (2007). Regulations and claims of functional foods. In Proceedings of the Fourth International FFNet meeting on functional foods.

Blaylock, J., Smallwood, D., Kassel, K., Variyam, J. \& Aldrich, L. (1999). Economics, food choices, and nutrition. Food Policy, 24, 269-86.

92 Jaunary - June 2013

Volume 11

Number 1

JISR-MSSE 
Bogue, J. Coleman, T. Sorenson, D. (2005). Determinants of consumers' dietary behavior for health-enhancing foods. British Food Journal, 107(1), 4-16.

Burton, S. \& Andrews, J. C. (1996). Age, product nutrition, and label format effects on consumer perceptions and product evaluations. The Journal of Consumer Affairs. 30(1), 68-89.

Buttriss, J. L. (1997). Food and nutrition; attitudes, beliefs and knowledge in the United Kingdom. American Journal of Clinical Nutrition, 65, 1985-95.

Chase, M. (1995). Lost in fat city: studies stir confusion over butter and oils. The Wall Street Journal, B1, July 10.

Childs, N. M. (1997). Functional foods and the food industry: Consumer, economic and product development issues. Journal of Nutraceuticals Functional and Medical Foods. $1,25-43$.

Childs, N. M., \& Poryzees, G. H. (1997). Foods that help prevent disease: Consumer cognitive and attitudinal determinants. Food Quality and Preference. 16, 45-57.

Dawson, J., Marshall, D., Taylor, M. Cummins, S., Parks, L. \& Andersen, A. (2008). Accessing healthy food availability and price of a healthy food basket in Scotland. Journal of Marketing Management, 24(9/10), 893-913.

De Graaf, C., Van der Gaag, M., Kafatos, A., Lennernas, M. \& Kearney, J. M. (1997). Stages of dietary change among nationally representative sample of adults in the European Union. European Journal of Clinical Nutrition, 51(2), 47-56.

De Jong, N., Ocke, M. C., Branderhorst, H. A. C. \& Friele, R. (2003). Demographic and lifestyle characteristics of functional food consumers and dietary supplement users. British Journal of Nutrition, 89, 273-281.

Dennison, C.M. \& Shepherd, R. (1995). Adolescent food choice: an application of the theory of planned behavior. Journal of Human Nutrition and Dietetics, 8, 9-23.

Dixon, J.M., Sarah, J.H. \& Banwell, C.L. (2006). Obesity, convenience and "phood”, British Food Journal. 108(8), 634-45.

Doyon, M. \& Labrecque, J. (2005). Functional Foods: A Conceptual Definition. Direction de la Recherche, Montre’al.

Drichoutis, A. C., Lazardis, P. \& Nayga, R. M. Jr. (2006). Consumers use of nutritional labels: a review of research studies and issues. Academy of Marketing Science Review, 2006 (9), 1-22.

Fishbein, M. \& Ajzen, I. 1975. Belief, attitude, intention, and behavior: An introduction to theory and research. Reading, MA: Addison-Wesley.

\begin{tabular}{lll|l}
\hline JISR-MSSE & Volume 11 & Number 1 & Jaunary - June 2013
\end{tabular}


FMI research \& Prevention-Rodale. (2004). Insights on whole grain from the $13^{\text {th }}$ Annual Shopping for Health Survey, Food Marketing Institute, Arlington, VA,

Gilbert, L. (2000). The functional food trend: What's next and what Americans think about eggs. Journal of the American College of Nutrition, 19, 507-512.

Giraud G. \& Trigui I. (2005). Effet de l'expérience émotionnelle sur les préférences du consommateur, une étude exploratoire appliquée aux produits alimentaires labellisés», Tendances du Marketing en europe, Congrès, Paris.

Golan, E., Macino, L. \& Unnevehr, L. (2009). Food policy: check the list of ingredients. Amber Waves, 7(2), 16-22.

Golodner, L.F. (1993). Healthy confusion for consumers. Journal of Public Policy and Marketing, 12(1), 130-132.

Haan, M., Kaplan, G.A. \& Camacho, T. (19870. Poverty and health. Prospective evidence from the Alameda County study. American Journal of Epidemiology, 125(6), 989-98.

Hale, J. L., Householder, B. J. \& Greene, K. L. (20030. The theory of reasoned action. In J. P. Dillard \& M. Pfau (Eds.), The persuasion handbook: Developments in theory and practice (pp. 259-286). Thousand Oaks, CA: Sage.

Harnack, L., Block, G., Subar, A., Lane, S. \& Brand, R. (1997). Association of cancer prevention related nutrition knowledge, beliefs, and attitudes to cancer prevention dietary behavior. Journal of the American Dietetic Association, 97(9), 957-65.

Heasman, M. \& Mellentin, J. (2001). The Functional Food Revolution, Healthy People, Healthy Profits, Earthcan, London.

Hernandez, B., S. L. Gortmaker, G. A., Colditz, K. E. Peterson, N. M. Laird, \& S. ParraCabrera. (1999). Association of obesity with physical activity, television programs and other form of video viewing among children in Mexico city. International Journal of Obesity and Relational Metabolism disorders, 23, 845-54.

Hilliam, M. (1996). Functional foods: The Western consumer viewpoint. Nutrition Reviews, 54, S189-S194.

IFIC. (2000). Functional foods. Attitudinal research. Washington, DC: International Food Information Council Foundation, IFIC.

IFIC. (2002). The consumer view on functional foods: Yesterday and today. Food Insight (May/June).

IFIC. (2004). Food Label and Calorie Research. 2004; Available at: http://www.ific.org/research/calorielabelres.cfm. Accessed 5 March, 2012.

IFIC. (2005). Qualified Health Claims. 2005; Available at:

http://www.ific.org/research/qualhealthclaimsres.cfm. 5 March, 2012.

\begin{tabular}{l|llll}
\hline 94 & Jaunary - June 2013 & Volume 11 & Number 1
\end{tabular} 
IFIC. (2006). Food and Health Survey: Consumer Attitudes toward Nutrition,Food and Health. Available at: http://www.ific.org/research/foodandhealthsurvey.cfm. Accessed 5 March, 2012.

Ippolito, P. M. \& Mathios, A. D. (1994). Nutrition information and policy: a study of US food production trends. Journal of Consumer Policy, 17(3), 271-305.

Khan, A.K. (1992). The Pure Food Laws: With latest case law 1, London

Koplan, J. P. \& Dietz W. H. (1999). Calorie imbalance and public health policy. Journal of the American Medical Association, 282, 1579-81.

Lusk, J. L. \& Rozan, A. (2005). Consumer acceptance of biotechnology and the role of second generation technologies in the USA and Europe. Trends in Biotechnology, 23, 386387 .

Lusk, J. L., House, L. O., Valli, C., Jaeger, S. R., Moore, M., Morrow, J. L., et al. (2004). Effect of information about benefits of biotechnology on consumer acceptance of genetically modified food: Evidence from experimental auctions in the United States, England, and France. European Review of Agricultural Economics, 31, 179-204.

Marmot, M. G., Kogevinas, M. \& Elston, M. A. (1987). Social/economic status and disease, Annual Review of Public Health, 8, 111-35.

Mazis, M. B. \& Raymond, M. A. (1997). Consumer perceptions of health claims in advertisements and on food labels. The Journal of Consumer Affairs, 31(1), 10-26.

Mintel. (2006). Functional Foods Market Intelligence. Mintel International Group Ltd.

Monneuse, M. O., Bellisle, F. \& Koppert, G. (1997). Eating habits, food and health-related attitudes and beliefs reported by French students. European Journal of Clinical Nutrition, 51, 46-53.

Moore, M. (2001), available at http://leda.law.harvard.edu/leda/data/376/MooreM.html viewed online on February 12, 2012

Moorman, C. (1990). The effects of stimulus and consumer characteristics on the utilization of nutrition information. Journal of Consumer Research, 17(3), 362-74.

Mueller, W. (1991). Who reads the label? American Demographics, 13(1), 36-40.

Nayga, R. M., Lipinski, D. \& Savur, N. (1998). Consumers' use of nutritional labels while food shopping and at home. The Journal of Consumer Affairs, 32(1),106-20.

Poulsen, J. B. (1999). Danish consumers' attitudes towards functional foods. Working Paper No. 62. Aarhus, Denmark: MAPP.

\begin{tabular}{lll|l}
\hline JISR-MSSE & Volume 11 & Number 1 & Jaunary - June 2013
\end{tabular}


Ruangdaraganon, N., N. Kotchabhakdi, U. Udomsubpayakul, C. Kunanusont and P. Suriyawongpausal. (2002). The association between television viewing and childhood besity: A National survey in Thailand. Journal of Medical Association of Thailand, 85(4), S1075-80.

Sejwacz, D. Ajzen, I. \& Fishbein, M. (1980). Predicting and understanding weight loss: Intentions, behaviours and outcome. In I. Ajzen and M. Fishbein (Eds.), Understanding attitudes and predicting social behavior (pp. 101-112). Eaglewoods Cliffs, NJ: Prentice Hall.

Sparks, P., Shepherd, R. \& Fewer, L.J. (1995), Assessing and structuring attitudes towards the use of gene technology in food production: The role of perceived ethical obligation. Basic and Applied Social Psychology, 16, 267-285.

Teisi, M. F., Levy, A. S. \& Derby, B. M. (1999). The effects of education and information source on consumer awareness of diet-disease relationships. Journal of Public Policy and Marketing, 18(2),197-207.

Turrell, G. (1997). Determinants of gender difference in dietary behavior. Nutrition Research, 17(7), 1105-20.

Turrell, G. (1998). Socio-economic differences in preference and their influence on healthy food purchasing choices. Journal of Human Nutrition and Dietetics, 11, 135-49.

Urala, N. \& La“hteenma“ ki, L. (2004). Attitudes behind consumers' willingness to use functional foods. Food Quality and Preference, 15(7-8), 793-803.

Urala, N. \& La“hteenma“ ki, L. (2006). Hedonic ratings and perceived healthiness in experimental food choices. Appetite, 47(3), 302-314.

Urala, N. \& La“hteenma“ ki, L. (2007). Consumers' changing attitudes towards functional foods. Food Quality and Preference, 18(1), 1-12.

Verbeke, W. (2005). Consumer acceptance of functional foods socio-demographic, cognitive and attitudinal determinants. Food Quality and Preference, 16(1), 45-57.

Verbeke, W. (2006). Functional foods: Consumer willingness to compromise on taste for health? Food Quality and Preference, 17(1-2), 126-131.

Wrick, K. L. (1995). Consumer issues and expectations for functional foods. Critical Reviews in Food Science and Nutrition, 35, 167-173. 


\section{Appendix}

Table 1: Descriptive Statistics

\begin{tabular}{|l|c|c|c|c|}
\hline Variables & Minimum & Maximum & Mean & Std. Deviation \\
\hline Health consciousness & 1 & 5 & 2.51 & 0.70 \\
\hline Health benefits & 1 & 4.3 & 2.35 & 0.49 \\
\hline Health beliefs & 0.8 & 4.2 & 2.14 & 0.56 \\
\hline Attitude nutrition/health claim & 1.0 & 4.6 & 2.89 & 0.47 \\
\hline Purchase intentions & 0.7 & 5 & 3.06 & 1.46 \\
\hline
\end{tabular}

Table 2: Respondent's Socio/demographic Profile

\begin{tabular}{|c|c|c|c|}
\hline Socio/demographic factors & Category & $\%$ & Numbers \\
\hline \multirow[t]{2}{*}{ Gender } & Male & 58 & 220 \\
\hline & Female & 41 & 158 \\
\hline \multirow[t]{2}{*}{ Marital Status } & Single & 50 & 186 \\
\hline & Married & 49 & 191 \\
\hline \multirow[t]{5}{*}{ Age } & $18-25$ & 34 & 128 \\
\hline & $26-35$ & 47 & 177 \\
\hline & $36-45$ & 16 & 60 \\
\hline & $46-50$ & 0.5 & 2 \\
\hline & 50 and above & 3 & 13 \\
\hline \multirow[t]{4}{*}{ Education } & Intermediate & 15 & 59 \\
\hline & Bachelors & 41 & 152 \\
\hline & Masters & 37 & 139 \\
\hline & MS \& above & 7 & 27 \\
\hline \multirow[t]{5}{*}{ Income } & $20-40 \mathrm{~K}$ & 21 & 80 \\
\hline & $41-60 \mathrm{~K}$ & 18 & 69 \\
\hline & $61-80 \mathrm{~K}$ & 20 & 75 \\
\hline & $81-100 \mathrm{~K}$ & 23 & 86 \\
\hline & 100K \& above & 18 & 68 \\
\hline
\end{tabular}


Table 3: Pearson Product Correlation Matrix

\begin{tabular}{|c|c|c|c|c|c|}
\hline Scales & $\begin{array}{l}\text { Health } \\
\text { consciousness }\end{array}$ & $\begin{array}{l}\text { Health } \\
\text { benefits }\end{array}$ & $\begin{array}{l}\text { Health } \\
\text { beliefs }\end{array}$ & $\begin{array}{l}\text { Attitude } \\
\text { NHC }\end{array}$ & $\begin{array}{l}\text { Purchase } \\
\text { intentions }\end{array}$ \\
\hline Health consciousness & 1 & & & & \\
\hline Health benefits & $0.370 * *$ & 1 & & & \\
\hline Health beliefs & -0.020 & $0.203 * *$ & 1 & & \\
\hline Attitude towards NHC & $0.382 * *$ & $0.341 * *$ & $-0.104 *$ & 1 & \\
\hline Purchase intentions & $0.196 * *$ & $0.126^{*}$ & $-0.146^{* *}$ & $0.136 * *$ & 1 \\
\hline
\end{tabular}

** Correlation is significant at the 0.01 level (2-tailed)

* Correlation is significant at the 0.05 level (2-tailed)

Table 4: ANOVA

\begin{tabular}{|l|r|r|r|r|r|}
\cline { 2 - 6 } \multicolumn{1}{c|}{} & \multicolumn{5}{c|}{ ANOVA sig. values } \\
\hline Variables & Gender & Marital status & \multicolumn{1}{c|}{ Age } & Education & Income \\
\hline Health Consciousness & 0.290 & 0.472 & 0.146 & 0.000 & 0.054 \\
\hline Health Benefits & 0.000 & 0.004 & 0.016 & 0.000 & 0.132 \\
\hline Health Beliefs & 0.002 & 0.001 & 0.029 & 0.356 & 0.053 \\
\hline Attitude NHC & 0.065 & 0.000 & 0.004 & 0.061 & 0.190 \\
\hline Pre-Purchase intentions & 0.279 & 0.123 & 0.230 & 0.002 & 0.033 \\
\hline
\end{tabular}

Table 5: Regression Analysis

\begin{tabular}{|l|c|}
\hline Hypotheses & $\begin{array}{c}\text { Adjusted R square } \\
\text { value }\end{array}$ \\
\hline $\begin{array}{l}\mathrm{H}_{1}: \text { Health consciousness, health benefits and health beliefs do not } \\
\text { explain variation in Attitude towards nutrition/health claims. }\end{array}$ & 0.208 \\
\hline $\begin{array}{l}\mathrm{H}_{2} \text { : Health consciousness, health benefits and health beliefs do not explain } \\
\text { variation in pre-purchase intentions. }\end{array}$ & 0.060 \\
\hline $\begin{array}{l}\mathrm{H}_{3}: \text { Attitude towards nutrition/health claims do not explains variation in pre- } \\
\text { purchase intentions. }\end{array}$ & 0.094 \\
\hline
\end{tabular}

